\title{
Bridging Research and Policy Processes for Climate Change Adaptation
}

\author{
Lars Otto Naess, Emily Polack and Blessings Chinsinga*
}

\begin{abstract}
This article addresses the link between research on adaptation to climate change and the related policy environment in which it operates. Drawing on recent case studies under the Climate Change Adaptation in Africa (CCAA) programme, we show how unpacking of policy processes through analysis of narratives, actors and politics can help shed light on important policy challenges for adaptation. The case studies reveal competing views on adaptation problems and strategies as well as their associated actors and political interests. They also identify spaces that could provide opportunities for policy engagement and influence, and ways of bridging research-policy gaps to support adaptation. We argue that such analyses are critical in order to provide greater coherence between evidence from adaptation research and emerging government policies and strategies on climate change in developing countries.
\end{abstract}

\section{Introduction}

With pledges of increasing funding for climate change responses in developing countries, there is growing awareness of the need to make sure that adaptation funding support is based on the best available evidence, as well as contributing to successful adaptation ${ }^{1}$ outcomes. Over recent years, much research has gone into analysing how individuals and societies may adapt to climate change, what support may be provided and how and what limitations exist to adaptation (Adger et al. 2009; Schipper and Burton 2009; Tschakert 2007). Attention is increasingly moving towards criteria for monitoring progress as well as defining and evaluating successful adaptation (Osbahr et al. 2010), centred on goals for improving resilience to a wide range of possible future climate risks amidst a range of other changes, and avoiding strategies that are 'maladaptive' by inadvertently increasing vulnerability (Barnett and O’Neill 2010).

However, there has so far been little research on how processes of adaptation support are unfolding in practice. This is surprising, considering that climate change responses, and in particular adaptation, will need contextspecific responses, and that policy responses will involve value judgements of both problems and priority actions (see Tanner and Allouche, this IDS Bulletin).

While there is growing understanding that adaptation planning needs to be considered first and foremost a political process (Eriksen and Lind 2009), these issues rarely receive much attention in practice. A broad consensus on the need for adaptation support hides differences in, for example, disciplinary starting points, goals, and views of farmers' knowledge - which would lead to different policy recommendations. O'Brien et al. (2007) show how different understandings of vulnerability can give rise to competing conceptions of adaptation; for example, a common discourse on climate change and agriculture focuses on changing climate risks and vulnerability as a result of land degradation and overuse of resources. The policy priority here is on improving climate projections and changes in farming systems. An alternative discourse focuses on vulnerability as a product chiefly of structures hindering access to alternative livelihood options and resources. In this discourse, priority actions include removing structural barriers to adjustments in livelihoods, and strengthening existing systems for tackling climate variability (Silva and Hiraldo 2010). 


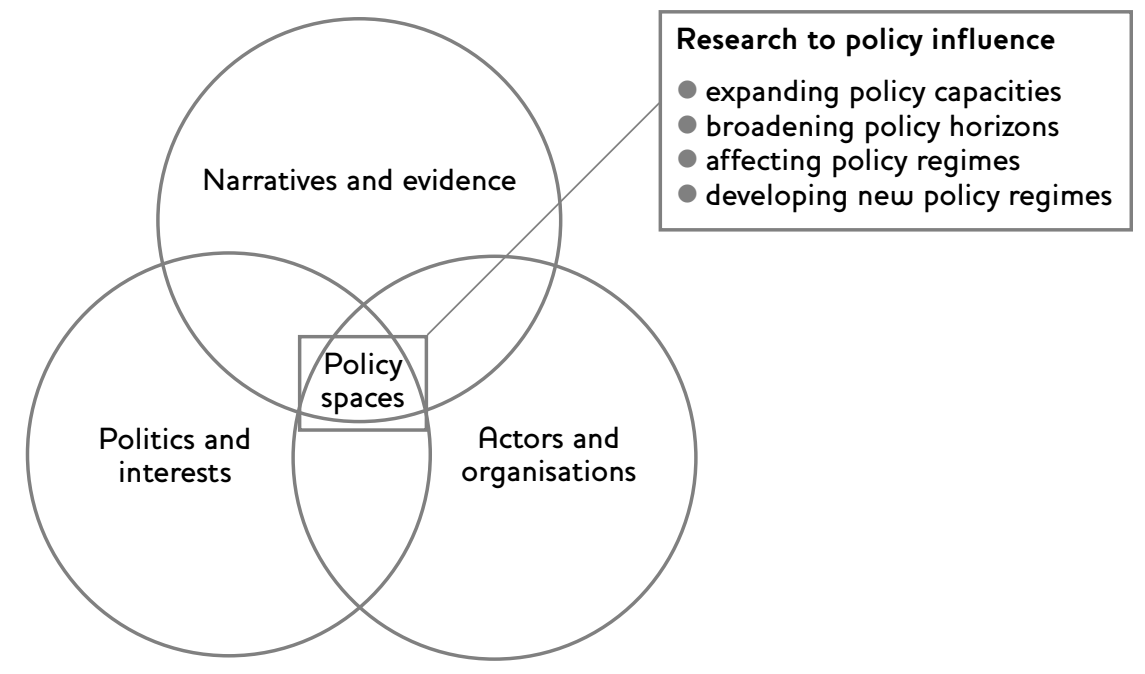

Source Adapted from Keeley and Scoones (2003) and Gaventa (2006).

We argue here that more attention needs to be given to understanding the processes through which different policy pathways are chosen and implemented. We focus on a particular set of challenges, namely linkages between adaptation research evidence and the policy context in which they are working, and ultimately hoping to influence. Examples are drawn from the DFID/IDRG-funded Research to Policy for Adaptation (RPA) project. The project aimed to increase the understanding of policy processes and consequently, the policy impact of CCAA (Climate Change Adaptation in Africa) programme partners. The RPA project case studies have analysed policy processes ${ }^{2}$ and potential policy spaces $^{3}$ related to their client CCAA projects in Kenya, Malawi and Tanzania, and from there, to help develop policy engagement strategies. Insights are also gained from ongoing work under the climate change theme of the DFID-funded Future Agricultures Consortium (FAC). ${ }^{4}$

The article has two main parts. In section two, we argue that political economy analysis of key narratives, actors and politics are important in order to uncover key policy challenges for adaptation, and helping to identify policy spaces for influence and engagement. For example, such analysis can help uncover which ideas in adaptation are gaining traction, and why, and the implications of different discourses. We introduce a methodological framework used in the RPA project to link adaptation research with related policy processes. In section three, we show how such analyses can help make a difference through improving the relevance of research to the policy context in which it is operating. Policy engagement and influence may require, among others, innovative ways of thinking, an awareness of the political context in which the research is situated and reflection of the goals that the research is trying to promote. We also discuss which practical methods and tools may be used.

Finally, we conclude that while it presents challenges for further research, analysis of policy processes and the development of policy engagement strategies can make critically important contributions towards improved adaptation decision-making processes. In doing so, we can create greater coherence between adaptation research and the government policies and strategies that are now emerging.

\section{Unpacking policy processes on adaptation}

Adaptation to climate change is a relatively new policy area, and policy responses in developing countries have only started to emerge over the last few years with pilot strategy documents such as National Adaptation Programmes of Action (NAPAs) developed by least developed countries (LDCs) and new funding mechanisms such as the Adaptation Fund and the Pilot Program for Climate Resilience (PPCR) (see Harmeling and 
Table 1 Narratives and policy engagement

\begin{tabular}{|c|c|c|}
\hline $\begin{array}{l}\text { RPA project case } \\
\text { study focus }\end{array}$ & Key narratives & Policy spaces and tools for engagement \\
\hline
\end{tabular}

Risk management, crop diversification and policy processes in Malawi (see

Chinsinga et al,, this IDS Bulletin)
- Food security is equivalent to maize production, bolstered by coinciding interests of donors, government and seed companies

- Alternative narrative on the need to promote crop diversification to support food security under climate change (promoted by CCAA project), but dominant narrative means lack of alternative seed and market for alternative crops

Indigenous knowledge (IK) and policy processes on climate risk management in Kenya (see Guthiga and Newsham, this IDS Bulletin)

Land and water management among pastoralists in Kenya (Ndirangu and Kamande 2011)
Model for predicting epidemics to manage increased malaria risk in Tanzania and Kenya (Mashindano et al. 2011; Mwamba 2011)
- Dominant narrative of powerful actors that local people's understanding of climate is unscientific, outdated and unreliable, coinciding with views of religious groups that indigenous knowledge is inappropriate recommending that $\mathrm{IK}$ should be replaced with scientifically based forecasting

- Alternative narrative that IK is key to understanding constraints and barriers, and that even if parts of the knowledge is 'outdated' the associated worldviews and institutions are still valid

- Pastoralism as agent of land degradation and potential for increasing conflicts over resources in a changing climate, suggesting that pastoralists should diversify livelihoods or abandon livestock altogether

- Pastoralism is an effective adaptive practice but is being threatened by extreme weather events and policies undermining their ability to adapt, suggesting that a holistic approach to land and water management policy is required to support adaptive practices

- Weak governance leading to poor infrastructure is the principal cause of malaria prevalence. Adaptation first and foremost requires tackling this

- Robust epidemic prediction models are critical to reducing increased malaria risk under climate change (linked to delivering timely and targeted net treatment and spraying and therefore perceived to be associated with commercial interests)
- Informal expert consultations through a National Consultative Group (NCG) used effectively to widen debate and policy spaces on topics such as 'what is food insecurity', creating informal spaces within otherwise formal processes

- Tackling when, where and how inputs are needed through seasonal and ecological zoning approach

- Policy space opening up with changing views on IK among powerful actors on basis of the CCAA project

- Learning centres have helped the project bring knowledge systems together

- Working with institutional frameworks such as university curricula to integrate meteorological science and IK

- ASAL (arid and semi-arid lands) strategy as a policy window for support that promotes a stronger policy for transhumance and activities that promote sustainable land management

- Civil education systems to promote representation of pastoralists in particular policy spaces, and promotion of literacy among pastoralists

- Engaging a wide set of actors from the outset, including health, climate change and governance actors

- Communicate the model in a way that steers the debate away from the robustness of the models but rather embrace and incorporate broad challenges and debates on tackling increased malaria prevalence under climate change 
Kaloga, this IDS Bulletin; Seballos and Kreft, this IDS Bulletin). In addition, some countries, such as Kenya, have developed their own national climate change response strategies (GoK 2010). In parallel, a large number of case studies and pilot activities have been carried out to map vulnerability and identify potential adaptation options in developing countries (McGray et al. 2007), but their relevance to and impact on government policies commonly remains unclear.

One way of bridging this gap is to unpack policy processes on adaptation. Figure 1 shows an analytical framework used for case studies under the RPA project, adapted from research on environmental policy processes in Africa and on policy spaces in power analysis (Keeley and Scoones 2003; Wolmer and Scoones 2005; Gaventa 2006). The framework brings together experiences from a range of disciplines and research areas, and was designed to analyse policies in a way that reflects the complexity, nonlinearity and 'messy' nature of policy processes. The framework uses three lenses to analyse policy processes, namely narratives/discourses, actors/networks and politics and interests.

Narratives are storylines that help identify competing ways of viewing a particular policy problem. Broad narratives around climate change include one which suggests that climate change is a grave threat to humankind. An alternative narrative is that climate change presents opportunities for improving human wellbeing. The actor component helps identify how different actors are working together and forming networks which promote certain approaches and define, for example, what types of knowledge counts as valid evidence in policy processes. Where messages are easily communicated and storylines match missions and measurable outputs in bureaucratic organisations, they become embedded in institutional structures or actor-network groups. The third element, politics, helps identify how politics of resource use and distribution or power relations need to be acknowledged, unravelled, or brought into the debate. Policy spaces, shown at the intersection between the three lenses, are the entry point for policy engagement and influence.

While it is beyond the scope of this article to outline all of these facets, Table 1 provides an overview of competing narratives identified in policy research case studies with their related
CCAA projects. It also highlights the policy spaces that have been identified (and in some cases used by CCAA projects) and examples of tools used for policy engagement. The first two examples in the table are then explored further below.

With regard to narratives, the investigation into a CCAA crop diversification initiative in Malawi has exposed conflicting government policies that undermine the potential contribution that such a project can make to adaptation (see Chinsinga et al., this IDS Bulletin). The challenge was identified as originating from narratives which equate food security with maize sufficiency at household and national level. While this underlies much of government agriculture policy, crop diversification is limited, as there are few mechanisms to ensure alternative crops are available for farmers. This narrative is strengthened by strongly ingrained perceptions of Malawians of alternative crops as 'inferior food'. The crop diversification for adaptation narrative is currently much weaker, despite the investments in related research and interventions such as the fertiliser subsidy programme (see Chinsinga et al., this IDS Bulletin).

A second example is a CGAA project in Kenya aiming to integrate indigenous and scientific knowledge on seasonal forecasting, and in turn help promote adaptation among farmers (see Guthiga and Newsham, this IDS Bulletin). While adaptation literature demonstrates the value of indigenous knowledge (IK) for adaptation (see, e.g. Tschakert 2007), strong narratives at national and sub-national scales underlying political action and policies throughout the last century weaken the potential for IK to enter mainstream debates on adaptation and to be adequately represented in policy fora. Some of the dominant discourses perceive indigenous practices as outdated and unreliable, and increasingly so in a changing climate. Research on indigenous knowledge is thus not likely to hold much influence until it achieves greater recognition at the national level. For example, while the discrete observations within indigenous knowledge is increasingly recognised, less recognition is given to the management systems, institutions and worldviews in which indigenous knowledge is embedded (see Guthiga and Newsham, this IDS Bulletin). This is of key importance to the knowledge systems' continued use in a changing climate. 


\section{Policy spaces and tools for engagement}

The examples above show how analysis of policy processes related to particular adaptation projects can help researchers and research participants consider the narratives that shape the way certain actors understand the research problem, and in turn the policy spaces that may be available or in some cases, in the process of opening up. Table 1 shows some of the policy spaces identified by the case studies, and some of the methods that were used (or identified as particularly relevant) by the client CCAA projects to help promote their findings. This is important not only because it can help better demonstrate policy impact of research funding and 'value for money' but also because it can help understand the dynamics and characteristics underpinning adaptive capacity and resilience, and what processes promote more robust and resilient societies in line with broader development challenges (Nelson et al. 2007; Adger et al. 2007).

Engaging policy spaces may involve a large degree of agreement between the narratives underlying the research and dominant narratives. In other cases, such as some of the RPA case studies, policy engagement requires challenging dominant narratives and received wisdom. Here, merely 'tinkering around the edges' to influence policies is not likely to be sufficient for the research evidence to have an impact on policies.

Analysis of policy processes may also help challenge the weaknesses in sectoral approaches to development, and divisions in national policies that limit local effective community natural resource management (Ndirangu 2011). This can, for example, help community-based adaptation (CBA) approaches address the gap between solutions from the community, and those emanating from national policymaking. Thus, policy analysis research can help community-based research initiatives understand the roles that institutions, regulatory environments and markets are playing at different scales, which in turn shape the spaces in which they have to evolve.

Furthermore, the local politics can give certain actors strong bargaining powers, overriding research evidence and limiting the choices of local farmers. For example, the Malawi case study found that a sugar company was using its bargaining power to block access to resources by local communities, and make them dependent on the company for their livelihoods, and serving their interests in the process (see Chinsinga et al., this IDS Bulletin). In a related case study in

Kenya, Brooks et al. (2009) argue that climate change may be an opportunity to challenge 'conventional wisdoms and established practices' relating to maize production in Kenya. However, such 'opportunities' are also seized by some actors to drive forwards more deeply existing/prevailing ideas/narratives. Brooks et al. (2009) also suggest, for example, that programmes that lock farmers into food systems promoted by particular organisations risk significantly undermining adaptive capacity. They offer as a 'counter-narrative' thinking about 'maize in a system' over maize as the food production system.

Many of the principles, tools and approaches from the case studies are in the form of bringing people together, such as learning centres and civil education systems (Kenya) or consultative groups (Malawi). Other cases include venues and framings as a way of bringing the issues - and competing narratives - together, either through university curricula (Kenya), and helping to broaden the debate on food security (Malawi) and malaria prevalence (Tanzania). For example, in the case of the malaria epidemic prediction model, some actors are not convinced that epidemic prediction and prevention models are an appropriate policy response to adaptation, based on a deep conviction that the priority should be on governance failures (e.g. in infrastructure to manage waste water). Opening a debate allows for acknowledgement of these perspectives and allows the model (MEPM) work to be framed in the context of a broad set of adaptive responses.

\section{Discussion and conclusions}

This article highlights some of the potential benefits that analysis of policy processes can give for understanding adaptation in practice and helping support evidence-based policies. The application of the framework also provides a number of challenges to researchers themselves. It requires an acknowledgement and openness from researchers on their own assumptions and that engaging with policy spaces makes them policy actors in their own right, not merely outside observers. Challenges to and shifts in dominant narratives takes considerable time. Indeed, the 
dominant narrative may be considered the most beneficial or detrimental depending on perspective and criteria for evaluation.

One of the key challenges is therefore to engage actors constructively in the longer term. For climate change, this is an even greater challenge given the time horizons and the urgency of climate change policy, and the directives of international funding mechanisms.

Acknowledgement of the politics underlying adaptation strategies may enable movement beyond the status quo in development practices, thereby challenging the underlying drivers of vulnerability. In some cases, research projects and programmes for adaptation may be maintaining the status quo, or even worsening vulnerability conditions (maladaptation) by continuing to work within dominant conceptual framings of the problem of climate change impacts on poverty, and within dominant modes of policymaking that can exclude alternative voices and perspectives.

The case studies show how the analysis of policy processes can make a difference in policy and practice by showing ways in which adaptation policy processes are being negotiated (questions, tools and methods) and how research/enquiry

\section{Notes}

* Research for this article was conducted under the Research to Policy for Adaptation project, funded through the Climate Change Adaptation in Africa (CCAA) programme. CCAA is a joint programme of the International Development Research Centre (IDRG) and the UK's Department for International Development (DFID). The research also benefited significantly from the Climate Change Theme of the Future Agricultures Consortium (FAC), a DFIDfunded partnership of leading independent research institutes working on African agricultural policy. The views expressed here are the views of the authors and do not represent the views or policies of IDS, DFID, or IDRC. can lead actors to think about the 'problem' in different ways and forge spaces for diverse voices and knowledge. As the case studies show, adaptation processes do not happen in a vacuum, but are populated by actors with a wide range of views, networks and political aims. By identifying policy spaces, such analysis can distil key considerations for improved success in policy engagement in adaptation research.

More broadly, the article tells us that policy processes research and engagement may improve the range of perspectives being considered on adaptation, and help questioning established beliefs and vested interests that are or are likely to be - involved in adaptation planning processes. None of the separate areas of analytical inquiry are new, but the way of understanding policy processes through the three lenses may help provide new perspectives and angles to existing adaptation research. Finally, through acknowledging that adaptation is inherently political, research design can be better shaped and made more relevant to key policy concerns and challenges by asking whether it understands the policy context, and the dynamic policy processes, and how and with whom might the research engage.

1 By adaptation, here we mean an 'adjustment in ecological, social, or economic systems in response to actual or expected climatic stimuli and their effects or impacts' (Smit et al. 2001: 881).

2 By policy processes, we here mean incremental, complex and non-linear processes encompassing actors with different views and discourses, networks and power relations, as described in e.g. Keeley and Scoones (2003).

3 By policy spaces we mean 'opportunities, moments and channels where citizens can act to potentially affect policies, discourses and decisions and relationships that affect their lives and interests' (Gaventa 2006: 26).

4 See www.future-agricultures.org 


\section{References}

Adger, W.N.; Lorenzoni, I. and O'Brien, K. (2009) Adapting to Climate Change: Thresholds, Values, Governance, Cambridge: Cambridge University Press

Adger, W.N.; Agrawala, S.; Mirza, M.M.Q.; Conde, C.; O'Brien, K.; Pulhin, J.; Pulwarty, R.; Smit, B. and Takahashi, K. (2007)

'Assessment of Adaptation Practices, Options, Constraints and Capacity', in M.L. Parry, O.F. Canziani, J.P. Palutikof, P.J. van der Linden and C.E. Hanson (eds), Climate Change 2007: Impacts, Adaptation and Vulnerability. Contribution of Working Group II to the Fourth Assessment Report of the Intergovernmental Panel on Climate Change, Cambridge: Cambridge University Press

Barnett, J. and O’Neill, S. (2010) 'EditorialMaladaptation', Global Environmental Change 20: 211-13

Brooks, S.; Thompson, J.; Odame, H.; Kibaara, B.; Nderitu, S.; Karin, F. and Millstone, E. (2009) Environmental Change and Maize Innovation in Kenya: Exploring Pathways In and Out of Maize, STEPS Working Paper 36, Brighton: STEPS Centre

Eriksen, S. and Lind, J. (2009) 'Adaptation as a Political Process: Adjusting to Drought and Conflict in Kenya's Drylands', Environmental Management 43.5: 817-35

Gaventa, J. (2006) 'Finding the Spaces for Change: A Power Analysis', IDS Bulletin 37.6: 23-33

GoK (2010) National Climate Change Response Strategy, Government of the Republic of Kenya

Keeley, J. and Scoones, I. (2003) Understanding Environmental Policy Processes: Cases from Africa, London: Earthscan/James \& James

Mashindano, O. and Odame, H. (forthcoming 2011) The Malaria Epidemic Prediction Model (MEPM) for Reducing Malaria Incidence in Kenya: Analysis of Policy Processes, RPA project Working Paper, Brighton: IDS

McGray, H.; Bradley, R. and Hammill, A. (2007) Weathering the Storm: Options for Framing Adaptation and Development, Washington DC: World Resources Institute

Mwamba, N. (forthcoming 2011) Adoption of The Malaria Epidemic Prediction Model (MEPM) for
Reducing Malaria Incidence in Tanzania, RPA project Working Paper, Brighton: IDS

Nelson, D.R.; Adger, W.N. and Brown, K. (2007) 'Adaptation to Environmental Change: Contributions of a Resilience Framework', Annual Review of Environment and Resources 32: 395-419

Ndirangu, L. and Kamande, P. (forthcoming $2011)$ Policy Processes and Adaptation among Pastoralists in Northern Kenya: The Case of Water and Land Use in Turkana District, RPA project Working Paper, Brighton: IDS

O'Brien, K.; Eriksen, S.; Nygaard, L.P. and Schjolden, A. (2007) 'Why Different Interpretations of Vulnerability Matter in Climate Change Discourses', Climate Policy 7.1: 73-88

Osbahr, H.; Twyman, C.; Adger, N. and Thomas, D. (2010) 'Evaluating Successful Livelihood Adaptation to Climate Variability and Change in Southern Africa', Ecology and Society 15.2

Schipper, E. and Burton, I. (2009) The Earthscan Reader on Adaptation to Climate Change, London: Earthscan

Silva, P. and Hiraldo, R. (2010) Mapping of Policy Processes in Africa on Climate Change and Agriculture: A Literature Review, Future Agricultures Consortium, Brighton: IDS

Smit, B.; Pilifosova, O.; Burton, I.; Challenger, B.; Huq, S.; Klein, R.J.T. and Yohe, G. (2001) 'Adaptation to Climate Change in the Context of Sustainable Development and Equity', in J.J. McCarthy, O. Canziani, N.A. Leary, D.J. Dokken and K.S. White (eds), Climate Change 2001: Impacts, Adaptation and Vulnerability. Contribution of the Working Group II to the Third Assessment Report of the Intergovernmental Panel on Climate Change, Cambridge: Cambridge University Press

Tschakert, P. (2007) 'Views from the Vulnerable: Understanding Climatic and Other Stressors in the Sahel', Global Environmental Change 17: 381-96

Wolmer, W. and Scoones, I. (2005) An Introduction to Policy Processes, Brighton: IDS 